\title{
POSSIBILITIES OF STEERING THE TRANSPORTATION PLANNING PROCESS IN THE FACE OF BOUNDED RATIONALITY AND UNBOUNDED UNCERTAINTY
}

\author{
Professor C. Jotin Khisty, \\ Department of Civil Engineering-Illinois Institute of Technology, Chicago, IL \\ E-mail: khisty@iit.edu
}

\section{INTRODUCTION}

Although there have been a substantial number of critical dissections in recent years on how to improve the transportation planning process, most of them have been based on a piecemeal rather than on a holistic, systemic inquiry. This extended abstract represents an exploratory systemic formulation of an innovative framework to organize and steer the transportation planning process in the face of bounded rationality, unbounded uncertainty. There are other related issues, such as wicked problems, complexity, and conflict that will also be examined. A systemic inquiry is essential because the links connecting these problems to one another and to the planning process are not as clear as many imagine. Although we are strong in applying the principles of the natural sciences to planning, we are weak in understanding the related core social, economic, and cultural issues for dealing with an enlightened society. In fact, our current knowledge about the complexity of these issues and their interactions is anything but complete.

The general prescriptive decision-making model used in the transport/land-use planning process, known as the Rational Planning Model (RPM), runs through five basic stages: 1 . Identify objectives 2. Identify alternative courses of action 3. Predict consequences of actions 4. Evaluate the consequences, and 5. Select the alternative in accord with our criteria of efficiency. Whilst the RPM emphasizes 'scientific efficiency' through rational decisionmaking, the RPM has come under attack in the last three decades on the grounds that the model's basic assumptions are violated when it is applied in practice. In fact, a crisis in the methods and practice of transportation planning has been widely acknowledged, and probably the five most serious ones are those connected with the: rationality, uncertainty, 'wickedness', complexity, and conflict embedded in the planning process. What follows is a preliminary examination of the issues. 


\section{BOUNDED RATIONALITY AND UNBOUNDED UNCERTAINTY}

Solving purely technical problems is comparatively simple, as compared to tackling those problems encountered in transportation engineering and planning which are associated with social, economic, and environmental, and ethical concerns, requiring subjective interpretations, all embedded in uncertainty (Khisty 2001). In addition, such planning problems are poorly structured and defy straightforward analysis and are thus basically unbounded. For example, a technical problem of traffic engineering could be closely linked to a land-use problem, with social, economic, environmental, ethically, and political implications. Naturally, there is no clear-cut boundary, and the "technical" problem we thought we originally faced has now transformed into a cluster of problems, often called a "problematique", because it has properties that none of its parts have. (Ackoff, 1999; Banathy, 1996)

Bounded rationality refers to the concept that human problem-solvers are rarely able to identify all possible solutions to the problems at hand and, therefore, settle for choices that seem to satisfy the required solution properties of a problem. Generally they make decisions that might otherwise be considered as suboptimal, or as Simon (1957) put is, "the behavior of human beings who 'satisfice' because they do not have the wits to maximize". Another theme that has haunted planners in almost every sector of planning is the problem of uncertainty. Nothing is more certain than the prevalence of uncertainty about consequences of even the simplest decisions. Uncertainty arises whenever a decision leads to more than one possible consequence. First, there is the uncertainty that stems from a lack of knowledge about the causal relations of the world and the consequent inability to predict the outcome of possible actions. Second, there is the uncertainty arising from an inability to comprehend present and future preference orderings among possible outcomes for a city. And thirdly, there is the nagging doubt that tastes and desires of the community will change over time, and so will the goals (O'Sullivan 1980).

The question of uncertainty is concerned with three questions: (a) How do decision makers conceptualize uncertainty? (b) How do decision makers cope with uncertainty? and, (c) what are the relationships between different concepts of uncertainty and different methods of coping? (Lipshitz and Strauss, 1997) Conceptualizing uncertainty in planning is highly subjective in the sense that different individuals may experience different doubts in identical situations about the future. The conception of uncertainty is also case-specific depending on its effects on the proposed action, resulting in hesitancy and confusion. It is useful to examine a set of common planning situations stemming from different means-ends configurations, as shown in Figure 1, based on Thompson's research (1967). If there is certainty about both means and ends connected with a specific project, than decision making boils down to a computational exercise, falling into cell $\mathrm{A}$. If on the other hand, our goals are certain but our technologies (or strategies) to attain our ends are limited, then decisionmaking entails a good deal of professional judgment, represented by cell B. Cell C 
represents the situation when the use of proven strategies, coupled with uncertain goals, calls for compromise among contending actors for coming up with an acceptable solution, And,

\begin{tabular}{|c|c|c|}
\hline ENDS & \multicolumn{2}{|c|}{ GOALS \& OBJECTIVES } \\
\hline MEANS & Certain & Uncertain \\
\hline$\underset{\text { Certain }}{7}$ & $\begin{array}{c}(\mathrm{A}) \\
\text { Computation }\end{array}$ & $\begin{array}{c}(\mathrm{C}) \\
\text { Compromise }\end{array}$ \\
\hline Uncertain & $\begin{array}{c}\text { (B) } \\
\text { Judgement }\end{array}$ & $\begin{array}{c}\text { (D) } \\
\text { "Inspiration" } \\
\text { or Chaos }\end{array}$ \\
\hline
\end{tabular}

Figure 1. Means-Ends Configurations

uncertainty about both our goals as well as our technologies (or strategies), then probably what is called for is 'inspirational leadership' or 'random groping', depending on how complicated the problem is, and this situation is represented by cell D. Planners have described this cell as "the land of the lost or crazy," because this is where the "wicked problems" reside (Khisty 2000).

If by rationality we mean a self-conscious process of using reasoned arguments to make and defend claims, there are indeed many choices available. There are three principal rationalities available with the means-ends framework. Instrumental (or technical) rationality has been used extensively, and is geared for controlling technical problems in an efficient and scientific way. On the other hand, communicative rationality, guides communicative action, meeting the validity claims of comprehensibility, truth, rightness, and sincerity, so necessary for mutual understanding and agreement. In more recent years communicative rationality is finding its way in transportation planning, when we deal with complex and messy open-ended problems, represented by cells B, C, and D of Figure 1 . Indeed, a combination of both instrumental and communicative rationality, directed by emancipatory interests is needed for decision making to be an enlightened social process (Habermas 1987).

\section{3 "WICKED” PROBLEMS}

In the world of planning problems connected with transportation, a distinction can be made between problems that can be well defined (or "tame" problems) and those that are illdefined. In the latter category, further distinction can be drawn, resulting in the sub-class of "wicked" problems. Ill-defined problems are ones where both ends and means of solutions are unknown, ambiguous, or uncertain at least at the outset of the planning exercise. However, there are many planning problems that are so ill-defined that they defy solution and thus fall in the category of "wicked" problems, in the sense that as social, 
environmental, and ethical problems, they elude straightforward solution (Rittel and Weber 1973).

Most planning problems are really "wicked" and can be characterized as follows: (1) There is no definite formulation of a wicked problem. (2) Wicked problems have no stopping rule, and one usually ends by saying, "that's good enough." (3) Solutions to wicked problems are neither true or false, but just good or bad; for instance there is no such thing as a true or false plan, but just a good or bad plan. (4) The solution to a wicked problem has no immediate and no ultimate test. (5) Every wicked problem is a one-shot operation. (6) Wicked problems do not have an exhaustive set of potential solutions. (7) Every wicked problem is essentially unique. And (8) Every wicked problem can be considered as a symptom of another problem. Khisty (2000) has elaborated on the place of wicked problems in transportation and the possibility of using abductive inferencing to tackle such problems.

\section{COMPLEXITY}

Transportation planning clearly falls in the category of designing complex systems because it has the following unique characteristics: it consists of a large number of elements; it consists of many interactions between elements; the attributes of the elements are not predetermined; the interactions between elements are loosely organized, non-linear, and probabilistic (rather than deterministic) in their behavior; the individual sub-systems, embedded in the larger system, evolve over time; subsystems are purposeful and generate their own goals; the system is subject to behavioral influences and open to the environment. Flood and Jackson (1991) have written extensively about complexity and its relationship to bounded rationality and unbounded uncertainty.

\section{CONFLICT AND COERSION}

Transportation systems are planned and managed by several actors, and these actors form a pluralistic system of their own, where issues of concern are discussed. Naturally, conflicts are ubiquitous, because the multidimensional and dynamic nature of planning is complex, subtle, and poorly understood. Conflicts generally arise because actors do not share common interests, values and beliefs. It is also possible that actors do not agree upon ends and means of planning, resulting in little chance of compromise being possible. Under such circumstances, some actors coerce others to accept decisions that are not compatable to their line of thinking (Flood and Jackson 1991). In complex-coercive situations, the true source of power is generally hidden, and this creates problems of its own. 


\section{WHAT ARE THE POSSIBILITIES OF STEERING?}

Each of the issues briefly described above is highly complex and examining all of them holistically is even more so. One way of envisioning what possibilities are feasible is to turn the dominant paradigm on its head, because if the existing approach of transportation planning is so problematic, surely it's dialectical opposite may have something to offer (Rosenhead 1989).

This paper proposes to critically examine the relationships among the issues briefly described above to the basic problem of bounded rationality and unbounded uncertainty. Having done that, some of the alternative paradigms noted below will be examined: 1. Suboptimizing by seeking alternative solutions through trade-offs. 2. Reducing the dependence on data demands using hard and soft data. 3. Resorting to greater simplicity and transparency to reduce conflicts. 4. Depending on citizen inputs and participation, using the 'bottom-up' rather than the 'top-down' approach. 5. Using Soft Systems Methodologies in conjunction with the traditional RPM. (such as Robustness Analysis and Checkland's Soft Systems Methodology). 6. Making use of deductive, inductive, and abductive inferencing in forecasting variables.

The potential for improving the transportation process is an opportunity to take up the challenge of examining and exploiting a variety of newer methodologies that can help decision-makers to complement the often opaque, inflexible, mathematical models of analysis being currently used (Khisty 2000).

\section{REFERENCES}

Ackoff, R. L. (1999). Ackoff's Best: His Classic Writings on Management. John Wiley \& Sons, N.Y.

Banathy, B. H. (1996). Designing Social Systems in a Changing World, Plenum Press, London.

Flood, R.L. and M.C. Jackson (1991). Creative Problem Solving. John Wiley \& Sons, Chichester, UK.

Habermas, J. (1987). Theory of Communicative Action, Vol. 1. Beacon Press, Boston, MA.

Khisty, C. J. (2000). Can Wicked Problems be Tackled through Abductive Inferencing? Journal of Urban Planning \& Development, ASCE. 126:3.

Khisty, C. J. (2001). Is Hypermobility a Challenge for Transportation Ethics and Systemicity? Systemic Practice \& Action Research. 14:5.

Lipshitz, R. and Strauss, O. 1997. Coping with Uncertainty: A Naturalistic Decision-Making Analysis. Organizational Behavior \& Human Decision Processes. 69:2. 
O’Sullivan, P. (1980). Transportation Policy: Geographic, Economic, and Planning Aspects. Barnes $\&$ Noble, NJ.

Rittel, H. and M. Weber (1973). Dilemmas in the General Theory of Planning. Politcal Science. 4 Rosenhead, J. 1989. Rational Analysis for a Problematic World. John Wiley \& Sons, Chichester, UK.

Simon, H. (1957). Models of Man, John Wiley \& Sons, New York.

Thomson, J. D. 1967. Organization in Action, McGraw-Hill Book Co. New York 